\title{
PNG SUPPLEMENT
}

\section{A retrospective study of tuberculosis outcomes in Gulf Province, Papua New Guinea}

\author{
I. Moses, ${ }^{1}$ S. Main,$^{2}$ R. J. Commons, ${ }^{2,3}$ B. Robertson,${ }^{4}$ A. Mek, ${ }^{5}$ M. Gale ${ }^{2}$
}

http://dx.doi.org/10.5588/pha.18.0069

Setting: Gulf Province, a rural area of mainland Papua New Guinea, is known to have one of the highest burdens of tuberculosis (TB) in the country.

Objectives: To describe the characteristics and outcomes of TB patients registered for first-line treatment in Kerema General Hospital in Gulf Province between January and December 2016.

Design: This was a retrospective cohort study using routinely collected programme data.

Results: Of 347 cases with a recorded TB site, 54\% were male and $32 \%$ were aged $<15$ years. No human immunodeficiency virus (HIV) status was recorded for $51 \%$ of cases. TB was bacteriologically confirmed in $23 \%$ of cases. Among the cohort, there were 145 extrapulmonary TB cases (42\%); the site of disease was unknown in $56 \%$ of these cases. Of the 297 cases with treatment outcome evaluated, $56 \%$ had a favourable outcome and $26 \%$ were lost to follow-up. On multivariable analysis, extrapulmonary TB (adjusted OR [aOR] 0.51, 95\% Cl 0.30$0.88, P=0.02)$ and bacteriologically confirmed TB (aOR $0.40,95 \% \mathrm{Cl} 0.21-0.77, P<0.01$ ) were associated with decreased odds of an unfavourable treatment outcome.

Conclusion: The study findings highlight the need to improve TB diagnosis, access to HIV testing, treatment adherence, patient support and the quality of TB programme data in Gulf Province.

T uberculosis (TB) ranks among the top 10 causes of death worldwide and is a major cause of morbidity and mortality in low- and middle-income countries, with an estimated 1.3 million deaths in 2017. ${ }^{1}$

In 2016, Papua New Guinea (PNG) was one of 30 high TB burden countries in the world. ${ }^{1}$ PNG has taken action to address the TB burden, including efforts to improve access to timely bacteriological confirmation of the disease. ${ }^{2}$ National data suggest, however, that the accurate diagnosis of TB remains a substantial challenge. Approximately $27 \%$ of all TB cases in PNG in 2016 were reported as 'sputum not done' or 'not available', and $42 \%$ were reported as extrapulmonary TB (EPTB). ${ }^{3}$ This burden of EPTB in PNG is substantially higher than the estimated global proportion of extrapulmonary cases $(\sim 15 \%){ }^{1}$

New diagnostic tools such as Xpert ${ }^{\circledR}$ MTB/RIF (Cepheid, Sunnyvale, CA, USA) have been rolled out in PNG since 2012 and have the potential to improve the timeliness and accuracy of TB diagnosis, including that of EPTB. ${ }^{4,5}$ Increasing population access to diag- nostic tools to enable bacteriological confirmation of TB disease remains an important task.

Gulf Province has been identified as one of three 'TB hotspot' provinces in PNG, ${ }^{6}$ with a case notification rate of 669 per 100000 population in 2016. ${ }^{3}$ Similar to many areas of PNG, TB services in Gulf Province face major challenges in reaching the population to provide care, as most people live in rural and remote villages. Access to tools for bacteriological confirmation is challenging and a high proportion of TB cases are diagnosed clinically, including extrapulmonary cases. A 2012 study at Kikori Hospital, Gulf Province, found that over $40 \%$ of TB cases were extrapulmonary, most of which were not bacteriologically confirmed. ${ }^{7}$

We undertook an operational research study to describe the clinical characteristics and treatment outcomes of all TB patients registered for first-line $\mathrm{TB}$ treatment at Kerema General Hospital, Kerema, Gulf Province, in 2016.

\section{METHODS}

\section{Study design}

This was a retrospective cohort study using routinely collected programme data.

\section{General setting}

PNG is a lower middle-income country of over 7 million inhabitants, approximately $80 \%$ of whom live in rural and remote areas. ${ }^{8}$

\section{Local setting}

Located in the south-western region of mainland PNG, Gulf Province (population of approximately $200000),{ }^{8}$ is made up of two districts: Kikori in the west and Kerema in the east.

Kerema General Hospital has an estimated catchment population of approximately 28000 from both urban and rural areas. ${ }^{8}$ It serves as a TB Basic Management Unit (BMU) in the district. Accessing health services at Kerema General Hospital is a significant challenge because of geographical barriers, as well as high transport costs.

Kerema General Hospital has the only laboratory that performs microscopy and Xpert testing in the eastern part of Gulf Province. In mid-2014, Médecins Sans Frontières (MSF) started TB activities in Kerema General Hospital with a focus on multidrug-resistant TB. All rifampicin-resistant specimens are sent for culture to the Central Public Health Laboratory in PNG's capital, Port Moresby, before being sent to the
AFFILIATIONS

1 National Department of Health, Kerema District, Gulf Province, Papua New Guinea (PNG)

2 Burnet Institute,

Melbourne, Victoria, Australia

3 Global Health Division, Menzies School of Health Research, Darwin, Northern Territory, Australia

4 Médecins Sans Frontières, Kerema District, Gulf Province, PNG

5 Papua New Guinea Institute of Medical Research, Goroka, PNG

CORRESPONDENCE Iraingo Moses Provincial Health Office P O Box 60 Kerema 311 Gulf Province

Papua, New Guinea e-mail: iraingomoses@gmail. com

mosesratipo@gmail.com

KEY WORDS low- and middle-income; operational research; extrapulmonary
Received 29 September 2018 Accepted 25 February 2019

PHA 2019; 9(S1): S38-S42 (C) 2019 The Union 
Queensland Mycobacterium Reference Laboratory (Herston, QLD, Australia) for drug susceptibility testing. Kerema General Hospital has the only radiography (X-ray) facility in Gulf Province.

\section{Study population}

This study sought to collect, analyse and report data for all TB patients on first-line treatment registered between January and December 2016 at Kerema General Hospital. As the data from patients registered in January 2016 could not be located, however, the study analysed the patient cohort enrolled between 1 February and 31 December 2016.

\section{Data sources}

The data were collected from the TB register at Kerema General Hospital. Variables collected were age, sex, place of residence, type of $\mathrm{TB}$, bacteriological confirmation (smear and Xpert results), human immunodeficiency virus (HIV) status, treatment history, site of EPTB and treatment outcome. These data were entered manually into a structured format and then transferred into an electronic database (EpiData v 3.1; EpiData Association, Odense, Denmark).

The definitions for cases and treatment outcomes were based on the 2012 PNG National TB Management Protocols. ${ }^{9}$ Cure is defined as a smear-positive patient who is smear-negative in the last month of treatment and on at least one previous follow-up examination. It is only applicable to patients who were initially smear-positive. Treatment failure is defined as a patient who is smear-positive at 5 months or later during treatment. It also applies to smear-negative patients who become smear-positive at 2 months. The place of residence was categorised according to the approximate time taken to reach the BMU site. Times were determined based on extensive local knowledge of the district and usual transport routes used by the population.

\section{Analysis and statistics}

Data were extracted and imported into Stata v 15 for analysis (StataCorp, College Station, TX, USA). Categorical variables were reported as numbers and percentages, and continuous variables as medians and interquartile ranges [IQRs]. Categorical variables were compared using the $\chi^{2}$ test and Fisher's exact test. Continuous variables were compared using the Wilcoxon rank sum test.

Treatment outcomes were categorised as favourable (cured and treatment completed) and unfavourable (died, lost to follow-up, treatment failure and unknown). Outcomes listed as not evaluated and transferred out were not included in the analysis of the treatment outcomes. Univariable logistic regression analysis was used to explore demographic and clinical factors associated with unfavourable treatment outcomes. Multivariable logistic regression was used to further explore this association; all available confounders were forced into this model. The association is reported as odds ratios (ORs) and 95\% confidence intervals (CIs). $P<0.05$ was considered statistically significant.

\section{Ethics approval}

Ethics approval to conduct this study was obtained from the PNG Medical Research Advisory Council (Port Morseby, PNG) and Alfred Hospital Ethics Committee (Melbourne, VIC, Australia).

\section{RESULTS}

Between 1 February 2016 and 31 December 2016, 349 cases were registered for first-line TB treatment. Table 1 summarises the clinical and demographic characteristics of the 347 cases with a recorded site of TB. Among these, 188 (54\%) were male and 145 (42\%) were registered as having EPTB. The median age of patients with EPTB and pulmonary TB was not statistically different (24 years, [IQR 8-40] vs. 30 years, [IQR 14-42]; $P=$ $0.08)$. However, there were significantly more children aged $<15$ years with EPTB than with pulmonary TB (59/145, 41\% vs. 51/202, 25\%; $P<0.01)$.

Seventy per cent of all cases lived within $3 \mathrm{~h}$ travel time of the BMU. There were 81 (23\%) bacteriologically confirmed cases. HIV status was not recorded in 179 cases (51\%). Among the 168 patients with a known status, 13 (8\%) were HIV-positive. Information on cotrimoxazole preventive therapy and antiretroviral therapy were missing for these patients.

Of the 349 registered cases, 52 (15\%) transferred out or did not have an outcome evaluated. Of the remaining 297 cases, $166(56 \%)$ had a favourable treatment outcome, 91 (31\%) were lost to follow-up, 21 (7\%) died, $1(<1 \%)$ had treatment failure and 18 (6\%) had an unknown outcome.

On multivariable analysis, EPTB (aOR 0.51, 95\%CI $0.30-0.88, P=0.02$ ) and bacteriologically confirmed TB (aOR 0.40, 95\%CI 0.21-0.77, $P<0.01$ ) were associated with decreased odds of an unfavourable treatment outcome (Table 2).

Among the 145 cases of EPTB, 81 (56\%) of patients had an 'unknown' site of disease recorded. Table 3 describes the EPTB cohort by site of disease. Only five of the 145 cases (3\%) were bacteriologically confirmed. Treatment success among EPTB patients was 55\%, which was similar to the overall cohort.

\section{DISCUSSION}

We found a high rate of EPTB diagnoses in the context of low rates of bacteriological confirmation and HIV testing. Successful treatment outcomes were well below the World Health Organization (WHO) targets. ${ }^{10}$ ЕРTB and bacteriologically confirmed TB were both associated with decreased odds of an unfavourable outcome.

Although more likely than clinically confirmed TB cases to have a favourable outcome, only $63 \%$ of bacteriologically confirmed TB cases completed treatment or were cured. This may be due to undetected drug-resistant $\mathrm{TB}$, or failure of the $\mathrm{TB}$ programme to adequately support patients.

The findings of this study are similar to those reported in previously published studies from rural settings in PNG, where high rates of EPTB, childhood TB and low rates of bacteriological confirmation have
ACKNOWLEDGEMENTS

This research was conducted as part of the first

Operational Research Course for Tuberculosis in Papua New Guinea (PNG). The specific training programme that resulted in this publication was developed and implemented by the Burnet Institute (Melbourne, VIC, Australia) in collaboration with the PNG Institute of Medical Research (Goroka) and University of PNG (Port Moresby), and supported by the PNG National Department of Health Emergency Response Taskforce for MDR and XDR-TB, the National TB Programme and Western Provincial Health Office, Daru, PNG. The model is based on the Structured Operational Research and Training Initiative (SORT IT), a global partnership led by the Special Programme for Research and Training in Tropical Diseases at the World Health Organization (WHO/TDR).

The authors wish to thank the following people and institutions which contributed to this research or to the programme from which the operational research was conducted for their support: the National Emergency Response Taskforce for MDR and XDR-TB Secretariat, Port Moresby, PNG; the Gulf Provincial Health Office, Kerema, PNG; Kerema General Hospital, Kerema, PNG; Médecins Sans Frontières, Kerema, PNG; the TB staff of Kerema General Hospital, Kerema, PNG; and the course facilitators and course participants. The authors also thank all the study participants and $\mathrm{W}$ Philip of the Burnet Institute (Kokopo, PNG).

The training programme was delivered as part of the Tropical Disease Research Regional Collaboration Initiative, which is supported by the Australian Government and implemented by Menzies School of Health Research (Darwin, NT, Australia) and the Burnet Institute.

The views expressed in this publication are the authors alone and are not necessarily the views of the Australian or PNG Governments. The funder had no role in study design, data collection and analysis, decision to publish or preparation of the manuscript.

Conflicts of interest: none declared. 
TABLE 1 Demographic and clinical characteristics of tuberculosis patients treated with first-line therapy in Kerema General Hospital, Kerema, Gulf Province, Papua New Guinea, February-December 2016

\begin{tabular}{|c|c|c|c|c|}
\hline Variables & $\begin{array}{c}\text { *Pulmonary tuberculosis } \\
(n=202) \\
n(\%)\end{array}$ & $\begin{array}{c}\text { *Extrapulmonary } \\
\text { tuberculosis } \\
(n=145) \\
n(\%)\end{array}$ & $\begin{array}{c}\text { Total } \\
(n=347) \\
n(\%)\end{array}$ & $P$ value \\
\hline Age, years median [IQR] & $30[14-42]$ & $24[8-40]$ & $27[9-40]$ & 0.08 \\
\hline \multicolumn{5}{|l|}{ Age, years } \\
\hline$<15$ & $51(25)$ & $59(41)$ & $110(32)$ & \multirow[t]{3}{*}{$<0.01$} \\
\hline$\geqslant 15$ & $150(74)$ & $85(59)$ & $235(68)$ & \\
\hline Unknown & $1(<1)$ & $1(<1)$ & $2(<1)$ & \\
\hline \multicolumn{5}{|l|}{ Sex } \\
\hline Male & $116(57)$ & $72(50)$ & $188(54)$ & \multirow[t]{3}{*}{0.14} \\
\hline Female & $86(43)$ & $72(50)$ & $158(46)$ & \\
\hline Unknown & 0 & $1(<1)$ & $1(<1)$ & \\
\hline \multicolumn{5}{|c|}{ Place of residence, distance time from BMU, $h$} \\
\hline$<3$ & $137(68)$ & $105(72)$ & $242(70)$ & \multirow[t]{3}{*}{0.47} \\
\hline$\geqslant 3$ & $63(31)$ & $40(28)$ & $103(30)$ & \\
\hline Unknown & $2(1)$ & 0 & $2(<1)$ & \\
\hline \multicolumn{5}{|l|}{ Previous treatment } \\
\hline New & $164(81)$ & $118(81)$ & $282(81)$ & \multirow[t]{2}{*}{0.96} \\
\hline Retreatment & $38(19)$ & $27(19)$ & $65(19)$ & \\
\hline \multicolumn{5}{|l|}{ Smear microscopy } \\
\hline Negative & $61(30)$ & $26(18)$ & $87(25)$ & \multirow[t]{3}{*}{$<0.01$} \\
\hline Positive & $59(29)$ & 0 & $59(17)$ & \\
\hline Unknown & $82(41)$ & $119(82)$ & $201(58)$ & \\
\hline \multicolumn{5}{|l|}{ Xpert result } \\
\hline M. tuberculosis not detected & $3(2)$ & 0 & $3(<1)$ & \multirow[t]{3}{*}{$<0.01$} \\
\hline M. tuberculosis detected & $39(19)$ & $5(3)$ & $44(13)$ & \\
\hline Unknown & $160(79)$ & $140(97)$ & $300(87)$ & \\
\hline \multicolumn{5}{|l|}{ Diagnostic method } \\
\hline Clinically confirmed & $126(62)$ & $140(97)$ & $266(77)$ & \multirow[t]{2}{*}{$<0.01$} \\
\hline Bacteriologically confirmed & $76(38)$ & $5(3)$ & $81(23)$ & \\
\hline \multicolumn{5}{|l|}{ HIV status } \\
\hline Non-reactive & $90(45)$ & $65(45)$ & $155(45)$ & \multirow[t]{3}{*}{0.71} \\
\hline Reactive & $9(4)$ & $4(3)$ & $13(4)$ & \\
\hline Unknown & $103(51)$ & $76(52)$ & $179(51)$ & \\
\hline
\end{tabular}

* Two patients with unknown site of TB were excluded.

$\mathrm{IQR}$ = interquartile range; $\mathrm{BMU}=$ Basic Management Unit; HIV = human immunodeficiency virus.

been described. This study highlights the ongoing challenges to ensure high quality TB diagnosis. ${ }^{7,11}$

One finding that is consistent among the limited amount of published literature on TB in PNG is the high rate of EPTB relative to other settings. $1,3,7,11$ Detailed investigation to determine whether this phenomenon represents inappropriate diagnosis or if the clinical manifestations of TB in PNG are different to other settings has not been undertaken. Since 2013, the WHO has recommended that all presumptive ЕРTB cases undergo Xpert testing. ${ }^{4,5}$ The PNG 2017 national guidelines on TB management are aligned with the WHO recommendations; ${ }^{12}$ however, implementation challenges, as well as other concerns, such as the feasibility of tissue biopsies in resource-limited locations, need to be addressed. A formal study of the high burden of EPTB would be valuable to guide the PNG TB programme.

The high rate of childhood TB reported in this study is consistent with previous reports in PNG. $3,7,11$ Children are estimated to account for approximately 10-20\% of all TB cases globally. ${ }^{13}$ The high proportion of children with $\mathrm{TB}$ found in our study could be due to overdiagnosis or may be a true indication of the burden of TB disease in children. High rates of child TB are worrying, not only because of the burden of illness for the affected children, but also because this potentially reflects high levels of recent community transmission of TB. ${ }^{14,15}$ Diagnosing TB in children is challenging as it can be difficult to obtain a specimen and the current diagnostic tools are not well adapted to children. ${ }^{13}$

Since the end of this study period, efforts to improve the use of available diagnostic tools (smear and Xpert assay) have been enhanced. Clinicians at the Kerema General Hospital TB clinic have been applying the National TB Programme's diagnostic algorithms for pulmonary TB and EPTB, including the use of Xpert as a primary diagnostic tool wherever possible. In addition, comprehensive staff training in the new guidelines, as well as in data quality, is being planned.

The low rates of HIV testing observed in this study are a matter of concern. Despite a national recommendation to offer HIV testing to all TB patients, there is variation between provinces and the national testing rate among TB patients is only $34.8 \% .^{3}$ The lack of high testing coverage makes it difficult to estimate the true proportion of TB-HIV co-infection in the country. ${ }^{16}$ At Kerema General Hospital, efforts to improve the diagnosis and management of TB-HIV coinfection have been enhanced since January 
TABLE 2 Factors associated with unfavourable outcomes among TB patients treated with first-line therapy in Kerema General Hospital, Kerema, Gulf Province, Papua New Guinea, February-December 2016

\begin{tabular}{|c|c|c|c|c|c|c|c|}
\hline Variables & $\begin{array}{c}\text { Total assessed } \\
(n=297) \\
n(\%)\end{array}$ & $\begin{array}{c}\text { Favourable } \\
\text { outcome } \\
(n=166) \\
n(\%)\end{array}$ & $\begin{array}{c}\text { Unfavourable } \\
\text { outcome } \\
(n=131) \\
n(\%)\end{array}$ & OR $(95 \% \mathrm{Cl})$ & $P$ value & aOR $(95 \% \mathrm{Cl})$ & $P$ value \\
\hline Age, years, median, [IQR] & $27[10-40]$ & $27[8-40]$ & $28[13-42]$ & - & & - & \\
\hline$<15$ & $95(32)$ & $59(35)$ & $36(28)$ & Reference & & Reference & \\
\hline$\geqslant 15$ & $201(68)$ & $107(65)$ & $94(72)$ & $1.44(0.87-2.37)$ & 0.15 & $1.72(0.99-3.00)$ & 0.06 \\
\hline Unknown & $1(<1)$ & 0 & $1(<1)$ & & & & \\
\hline \multicolumn{8}{|l|}{ Sex } \\
\hline Male & $163(55)$ & $86(52)$ & $77(59)$ & Reference & & Reference & \\
\hline Female & $133(45)$ & $80(48)$ & $53(41)$ & $0.74(0.47-1.18)$ & 0.20 & $0.67(0.41-1.10)$ & 0.11 \\
\hline Unknown & $1(<1)$ & 0 & $1(<1)$ & & & & \\
\hline \multicolumn{8}{|l|}{ Type of TB } \\
\hline РTB & $167(56)$ & $85(51)$ & $82(63)$ & Reference & & Reference & \\
\hline EPTB & $129(43)$ & $80(48)$ & $49(37)$ & $0.63(0.40-1.01)$ & 0.06 & $0.51(0.30-0.88)^{*}$ & 0.02 \\
\hline Unknown & $2(1)$ & $1(1)$ & 0 & & & & \\
\hline \multicolumn{8}{|l|}{ Place of residence } \\
\hline Within $3 \mathrm{~h}$ of $\mathrm{BMU}$ & $224(75)$ & $131(79)$ & $93(71)$ & Reference & & Reference & \\
\hline$\geqslant 3 \mathrm{~h}$ from BMU & $71(24)$ & $35(21)$ & $36(28)$ & $1.45(0.85-2.48)$ & 0.18 & $1.32(0.76-2.32)$ & 0.33 \\
\hline Unknown & $2(1)$ & 0 & $2(2)$ & & & & \\
\hline \multicolumn{8}{|l|}{ Treatment history } \\
\hline New & $243(82)$ & $140(84)$ & $103(79)$ & Reference & & Reference & \\
\hline Retreatment & $54(18)$ & $26(16)$ & $28(21)$ & $1.46(0.81-2.64)$ & 0.20 & $1.39(0.75-2.60)$ & 0.30 \\
\hline \multicolumn{8}{|l|}{ Diagnostic method } \\
\hline Clinically confirmed & $222(75)$ & $119(72)$ & $103(79)$ & Reference & & Reference & \\
\hline Bacteriologically confirmed & $75(25)$ & $47(28)$ & $28(21)$ & $0.69(0.40-1.18)$ & 0.17 & $0.40(0.21-0.77)^{*}$ & $<0.01$ \\
\hline \multicolumn{8}{|l|}{ HIV status } \\
\hline Non-reactive & $132(44)$ & $78(47)$ & $54(41)$ & Reference & & Reference & \\
\hline Reactive & $12(4)$ & $5(3)$ & $7(5)$ & $2.02(0.61-6.71)$ & 0.25 & $1.87(0.54-6.51)$ & 0.32 \\
\hline Unknown & $153(52)$ & $83(50)$ & $70(53)$ & $1.21(0.76-1.95)$ & 0.41 & $1.16(0.70-1.90)$ & 0.57 \\
\hline
\end{tabular}

${ }^{*} P<0.05$.

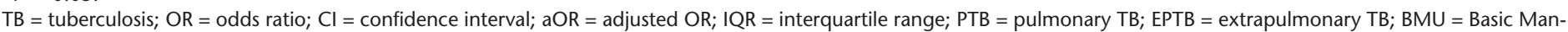
agement Unit; HIV = human immunodeficiency virus.

2018. This has included improving referral pathways between the TB and HIV clinics, improving TB screening among HIV patients and strengthening the provision of isoniazid preventive therapy to HIV-positive individuals without active TB.

A key strength of the study is that it reflects the ground reality of TB programme activities in a low-resource, rural setting in PNG. Our study provides an insight into the quality of TB control efforts in a high TB burden region and identifies key improvement opportunities.

One limitation of the study was the quality of the data available for analysis. The completeness and accuracy of programme data in the Kerema General Hospital BMU TB register was identified as a key issue that needs to be addressed. It should be noted that one month of data could not be located due to a missing register. Also, records indicate that a high proportion of EPTB cases had an 'unknown' site of disease. Reliable health data are critical for generating evidence to support decision-making and improve health service delivery. ${ }^{17,18}$

A lack of information on the TB site and the low rate of bacteriological confirmation made it difficult to analyse the EPTB cohort in detail. Similarly, our ability to investigate the risk factors for unfavourable outcomes was limited by the lack of complete

TABLE 3 Site of extrapulmonary tuberculosis diagnosed in patients treated with first-line therapy in Kerema General Hospital, Kerema, Gulf Province, Papua New Guinea, February-December 2016

\begin{tabular}{|c|c|c|c|c|c|c|c|}
\hline Variables & $\begin{array}{c}\text { Lymph node } \\
n(\%)\end{array}$ & $\begin{array}{l}\text { Abdominal } \\
n(\%)\end{array}$ & $\begin{array}{c}\text { Meningitis } \\
n(\%)\end{array}$ & $\begin{array}{l}\text { Spinal } \\
n(\%)\end{array}$ & $\begin{array}{l}\text { Other } \\
n(\%)\end{array}$ & $\begin{array}{l}\text { Unknown } \\
n(\%)\end{array}$ & $\begin{array}{l}\text { Total } \\
n(\%)\end{array}$ \\
\hline Total & $36(25)$ & $7(5)$ & $2(1)$ & $8(6)$ & $14(10)$ & $78(54)$ & $145(100)$ \\
\hline $\begin{array}{l}\text { Age, years, median } \\
\text { [IQR] }\end{array}$ & $13[8-30]$ & $40[21-50]$ & 11 [9-13] & $40[32-52]$ & $24[8-40]$ & $24[6-40]$ & $24[8-40]$ \\
\hline $\begin{array}{l}\text { Bacteriologically } \\
\text { confirmed }\end{array}$ & $3(8)$ & 0 & 0 & 0 & $1(7)$ & $1(1)$ & $5(3)$ \\
\hline $\begin{array}{l}\text { Successful treatment } \\
\text { outcome }\end{array}$ & $22(59)$ & $4(57)$ & $1(50)$ & $5(62)$ & $7(50)$ & $41(53)$ & $80(55)$ \\
\hline
\end{tabular}

$\mathrm{IQR}=$ interquartile range. 
and accurate information on key variables, including HIV status and 'time to BMU'. We estimated the 'time to BMU' based on local knowledge; however, this could not be validated.

\section{CONCLUSION}

The overall findings of this study showed that diagnostic assessment for TB and for TB-HIV coinfection remain a major challenge for Kerema General Hospital. Incompleteness of data collection is also a challenge. Interventions to address these issues include enhanced training for staff in the new national guidelines, with a special emphasis on optimising diagnosis.

\section{References}

1 World Health Organization. Global tuberculosis report, 2018. WHO/CDS/ TB/2018.20. Geneva, Switzerland: WHO, 2018.

2 Papua New Guinea Government. National Tuberculosis Strategic Plan (NSP) for Papua New Guinea. Port Moresby, PNG: PNG Government, 2015.

3 Aia P, Wangchuk L, Morishita F, et al. Epidemiology of tuberculosis in Papua New Guinea: analysis of case notification and treatment-outcome data, 2008-2016. Western Pac Surveill Response J 2018; 9: 1-11.

4 World Health Organization. Automated real-time nucleic acid amplification technology for rapid and simultaneous detection of tuberculosis and rifampicin resistance: Xpert MTB/RIF system for the diagnosis of pulmonary and extrapulmonary TB in adults and children: policy update, 2013. WHO/ HTM/TB/2013.16. Geneva, Switzerland: WHO, 2013.

5 World Health Organization. Xpert MTB/RIF implementation manual: technical and operational 'how-to'; practical considerations, 2014. WHO/HTM/ TB/2014.1. Geneva, Switzerland: WHO, 2014
6 National Department of Health, Papua New Guinea. Standard operating procedure: management of drug-resistant tuberculosis, 2017. Port Moresby, Papua New Guinea: National Tuberculosis Programme, 2017.

7 Cross GB, Coles K, Nikpour M et al. TB incidence and characteristics in the remote Gulf Province of Papua New Guinea: a prospective study. BMC Infect Dis 2014; 14: 93.

8 National Statistical Office, Papua New Guinea. National Population and Housing Census 2011. Port Moresby, Papua New Guinea: NSO, 2014.

9 National Department of Health, Papua New Guinea. National Tuberculosis Management Protocol, 2012. Port Moresby, Papua New Guinea: NDH, 2012.

10 World Health Organization. The End TB Strategy 2015. Geneva, Switzerland: WHO, 2015.

11 Diefenbach-Elstob T, Graves P, Dowi R, et al. The epidemiology of tuberculosis in the rural Balimo region of Papua New Guinea. Trop Med Int Health 2018; 23: 1022-1032.

12 National Department of Health, Papua New Guinea. National Tuberculosis Management Protocol, 2017. Port Morseby, Papua New Guinea: NDH, 2017.

13 World Health Organization. Roadmap for childhood tuberculosis: towards zero deaths. Geneva, Switzerland: WHO, 2013.

14 Marais BJ, Gie RP, Schaaf HS, et al. The natural history of childhood intra-thoracic tuberculosis: a critical review of literature from the pre-chemotherapy era. Int J Tuberc Lung Dis 2004; 8: 392-402.

15 Middelkoop K, Bekker L-G, Morrow C, Lee N, Wood R. Decreasing household contribution to tuberculosis transmission with age: a retrospective geographic analysis of young people in a South African township. BMC Infect Dis 2014; 14: 221.

16 Viney K, Hoy D, Roth A, Kelly P, Harley D and Sleigh A. The epidemiology of tuberculosis in the Pacific 2000-2013. Western Pac Surveill Response J 2015; 6: 56-67.

17 Ndabarora E, Chipps JA, Uls L. Systematic review of health data quality management and best practices at community and district levels in low- and middle-income countries. Information Development 2013; 30(2): 103-120.

18 World Health Organization. Improving data quality: a guide for developing countries, 2003. Geneva, Switzerland: WHO, 2003.
Contexte: La Province du Golfe est une zone rurale de la partie continentale de la Papouasie Nouvelle Guinée connue pour être parmi les plus affectées par la tuberculose (TB) dans le pays.

Objectifs : Décrire les caractéristiques et l'évolution des patients TB enregistrés pour un traitement de première ligne à l'hôpital général de Kerema dans la Province du Golfe entre janvier et décembre 2016. Schema : Une étude rétrospective de cohorte basée sur des données de programme recueillies en routine.

Resultats : Sur 347 cas dont le site de TB a été enregistré, 54\% ont été des hommes et $32 \%$ avaient moins de 15 ans. Le statut $\mathrm{VIH}$ n'a pas été enregistré chez $51 \%$ des cas. La TB a été confirmée par bactériologie dans $23 \%$ des cas. Dans la cohorte, il y a eu 145 cas de
TB extra pulmonaire (42\%) et le site de la maladie est resté inconnu dans $56 \%$ des cas. Sur 297 cas dont le résultat du traitement a été évalué, il a été favorable dans $56 \%$ des cas et $26 \%$ ont été perdus de vue. En analyse multivariée, la TB extra pulmonaire (OR ajusté [ORa] 0,51 ; IC95\% 0,30-0,88, $P=0,02$ ) et la TB confirmée par bactériologie (ORa 0,40; IC95\% 0,21-0,77, $P<0,01$ ) ont été associées à une diminution du risque de résultats défavorables du traitement.

Conclusion: Les résultats de cette étude mettent en lumière le besoin d'améliorer le diagnostic de la TB, l'accès au test VIH, l'observance du traitement, le soutien aux patients et la qualité des données du programme TB dans la Province du Golfe.
Marco de Referencia: La provincia del Golfo es una zona rural continental de Papúa Nueva Guinea, donde existe una de las cargas de morbilidad por tuberculosis (TB) más alta del país.

Objetivos: Describir las características y los desenlaces clínicos de los pacientes con TB registrados para recibir un tratamiento de primera línea en el Hospital General de Kerema en la provincia del Golfo, entre enero y diciembre del 2016.

Método: Fue este un estudio retrospectivo de cohortes a partir de los datos programáticos corrientes.

Resultados: De los 347 casos en los cuales se había consignado la localización de la TB, el $54 \%$ era de sexo masculino y el $32 \%$ era menor de 15 años de edad. No se contaba con la situación frente al virus de la inmunodeficiencia humana en el $51 \%$ de los casos. Se confirmó bacteriológicamente el diagnóstico de TB en el $23 \%$ de los casos. La cohorte comportaba 145 casos de TB extrapulmonar (42\%) y se desconocía la localización en el $56 \%$ de estos pacientes. De los 297 pacientes en quienes se evaluó el desenlace terapéutico, el 56\% fue favorable y hubo un $26 \%$ de pérdidas durante el seguimiento. Según el análisis multivariante, los factores asociados con una menor probabilidad de desenlace terapéutico desfavorable fueron la TB extrapulmonar TB (cociente de posibilidades ajustado [aOR, por odds ratio]: 0,51, intervalo de confianza [IC] del 95\% 0,30-0,88; $P=0,02$ ) y la TB con confirmación bacteriológica (aOR: 0,40; IC95\% 0,21$0,77 ; P<0,01)$.

Conclusión: Los resultados del presente estudio destacan la necesidad de mejorar el diagnóstico de la TB, el acceso a las pruebas del VIH, la adhesión al tratamiento, el apoyo a los pacientes y la calidad de los datos del programa de TB en la provincia del Golfo.
Public Health Action (PHA) The voice for operational research. Published by The Union (www.theunion.org), PHA provides a platform to fulfil its mission, 'Health solutions for the poor'. PHA publishes high-quality scientific research that provides new knowledge to improve the accessibility, equity, quality and efficiency of health systems and services.
e-ISSN 2220-8372

Editor-in-Chief: Dermot Maher, MD, Switzerland

Contact: pha@theunion.org

PHA website: http://www.theunion.org/what-we-do/journals/pha Article submission: http://mc.manuscriptcentral.com/pha 